\title{
Open Access and the Free Flow of Scientific Information
}

\section{David J. Eaglesham}

The open communication of scientific results holds a central place in the scientific process. Scientific progress comes through public disclosure and open exchange of information, with members of the scientific community learning from each other in a collective act of mutual shoulder-standing. As part of this process, the ultimate test of all science lies in the Darwinian "free marketplace of ideas," where peer-reviewed papers, published in the open literature, are tested under the scrutiny of the broader scientific community. Good ideas are expanded upon and grow, mistakes are corrected, bad ideas are abandoned and wither away. Publication is central to the scientific community.

Like any other community need, this creates a business opportunity. There is money to be made in publishing scientific papers. A publishing industry has grown up around the scientific community like Virginia creeper round an oak. Scientific publishing was a $\$ 7$ billion dollar industry in 2004, with profits in the region of around $34 \%$ for industry leaders. Like any other industry, it is driven to grow, and so the number of journal titles proliferates while the content in each seems ever more dilute. The International Association of Scientific, Technical \& Medical Publishers estimates that there are now over 2,000 STM publishers worldwide, publishing over 1.2 million articles per year via approximately 16,000 journals. The price is borne by the enduser scientists, directly or indirectly. The cost of scientific publications to libraries and subscribers grew 180\% between 1990 and 2000, and continues to skyrocket.* Current pricing is prohibitive for many

\footnotetext{
${ }^{*}$ Figures come from the U.K. parliamentary report, "Scientific Publications: Free for All? Tenth Report of Session 2003-04, Volume I: Report," HC 399-I, published July 20, 2004, by authority of the House of Commons, and accessible on-line at http://www.publications. parliament.uk/pa/cm200304/cmselect/ cmsctech/399/399.pdf.
}

research institutions, even in the developed world. All of which is strange, considering that, in general, scientific publishers do not fund the science, do the research, write the papers, review for accuracy, or edit for quality. We do that. They just print the journal and then sell it back to us.

\section{"There is a tantalizing sense that we are only separated from a truly seamless world of scientific knowledge by a bad business model for how we publish."}

Modern information technology is changing this. It is removing from the publishers the burden of printing: now they just sell us the content and we print it. But it is also lowering barriers to information exchange and making it easier for the world's scientific communities to work together seamlessly. The flow of information around the planet is relentless and unstoppable. And the scientific world is extraordinarily transparent. Searches on information are changing the way we think about problems. The average researchers sitting at their desk can now reach out to tap the world's knowledge resources. We can "google" almost any topic and rapidly get routed to the relevant research and researchers and probably some rough description of the work. Google Scholar, my personal favorite, lets us google our way to the links for the scientific papers that we are looking for-assuming, of course, that we have a paid-up subscription to the journal. Universities have an obligation to

Material Matters is a forum for expressing personal points of view on issues of interest to the materials community. subscribe very broadly (regardless of cost), and as a result, journal subscriptions consume an enormous fraction of the campus budget. Most U.S. corporations can afford access to only a small fraction of the bewildering array of journals (start-ups usually rely on access through a university library). For scientists in many developing countries, the cost of access to the information is prohibitive, and they are effectively excluded from joining the club. Too often, we have the ability to google to within a click of the paper but can't make that last connection. There is a tantalizing sense that we are only separated from a truly seamless world of scientific knowledge by a bad business model for how we publish.

There are groups both in the United States (led by the National Institutes of Health) and in Europe (notably, the United Kingdom) currently advocating a shift toward "open access" publishing. This covers a multiple set of mechanisms that allow the end user free and unrestricted access to all the world's published papers. There are a variety of business models for this, page charges being the simplest and most obvious. There are also mixed models such as the one currently being advocated by NIH, where users would have to subscribe to get "current contents," editorials, and recent papers (generally less than 12 months old) but have open access to the archival publications on PubMed Central. This would lead to continuing strength for premium journals that have strong editorial content but would almost certainly be fatal to boutique technical journals and many scientific publishers. Almost any open-access approach that can be imagined would lead to the collapse of many marginally profitable small-circulation journals. It is hard to see how this could be a bad thing. In addition to modified business models, there is also a strong push (very strong in the United Kingdom) to create user-owned repositories of papers that can be openly downloaded (so that every author and every university would have their own public database of published pdf files). Contrary to popular belief, this practice is permitted by almost all publishers, even Elsevier, at no cost to the user. The open-access movement envisions that scientific papers will become a global network of free information for all the world's scientists.

The Materials Research Society, of course, is not just representing the end user here: we are also part of the problem. MRS has three main strands of publications: MRS Bulletin, the Proceedings, and the Journal of Materials Research 
$(J M R)$. All of them are published on papyrus, and none of them are (yet) fully open access, although all three are available on-line and sections of the Bulletin are open access. Like most technical societies (except the American Chemical Society), we view our publications in a not-for-profit light. All Proceedings and issues of MRS Bulletin are available to members on the Web site, and downloads (up to $1,028,400$ ) and site visits (up to $\sim 131,000$ ) indicate that they provide a valuable member benefit. Because we view them as a member benefit, we have maintained them as exclusive (member log-in required), contrary to the principles of open access. Currently, MRS Bulletin

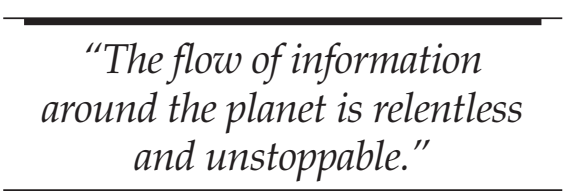

expenses are covered about $50 / 50$ by membership dues heavily-subsidized by advertising and $J M R$ by subscriptions and page charges, while the cost of the Proceedings is covered by sales of the hard-copy Blue Books. JMR and the Proceedings (even MRS Bulletin) will face challenges if we transition to an openaccess model. Nonetheless, all MRS's publications are being actively studied at the moment by the Information Services
Committee with a view to understanding the right way to move them into the online world.

Open access looks to me like the vision of the future. We are so close to a world of seamless information exchange that I cannot believe that we will not close the gap. I think MRS can play a small role in making that happen. And at a minimum, I encourage our members to post their papers on-line and let me google them to my heart's content.

David J. Eaglesham, of the New Business and New Products Group at Applied Materials, is the Immediate Past President of the Materials Research Society. 